Pengembangan Rekayasa dan Teknologi, Vol 13, No. 2, Desember 2017, pp 47-51

p-ISSN: 1410-9840 \& e-ISSN: 2580-8850

http://journals.usm.ac.id/index.php/jprt/index

\title{
DESAIN SISTEM ROOFTOP OFF GRID PANEL SOLAR PHOTOVOLTAIC
}

\author{
Harmini $^{1}$, Titik Nurhayati ${ }^{2}$ \\ ${ }^{1,2}$ Jurusan Teknik Elektro, Fakultas Teknik Universitas Semarang, Semarang Indonesia 50196 \\ Jl. Soekarno Hatta Tlogosari, Semarang Telp (024)6702757 \\ e-mail: harmini@usm.ac.id ${ }^{1}$,ttknur@usm.ac.id ${ }^{2}$
}

\begin{abstract}
ABSTRAK
Pada saat ini hampir semua rumah tempat tinggal menggunakan sumber energi dari jaringan PLN. Sumber energi listrik yang disediakan oleh PLN sebisa mungkin dilakukan penghematan dalam pemakaian listrik. Salah satu cara yang digunakan adalah setiap rumah menggunakan Roof top panel solar photovoltaic, hal ini bertujuan untuk mengurangi ketergantungan sumber energi dari PLN. Berdasarkan hal tersebut maka perlu dilakukan perancangan dalam pengaplikasian Roof top solar panel. Pada penelitian ini akan dirancang sistem Roof top off grid panel SPV sebagai sumber alternatif energi listrik. Perancangan diperuntukkan untuk sistem Solar Home System (SHS) atau rumah tempat tinggal dengan acuan radiasi matahari di wilayah Jawa Tengah. Sistem rooftop off grid solar photovoltaic dirancang dengan menggunakan komponen panel SPV, baterai, inverter dan charge controller. Kapasitas daya yang dirancang adalah 1.576,2 Watt dan konsumsi energi per hari sebesar 4.260 Wh Jumlah baterai sebanyak 12 unit dengan kapasitas masingmasing $310 \mathrm{Ah}$, panel SPV sebanyak 6 Unit kapasitas $225 \mathrm{Wp}$, inverter 1 unit sebesar 1000 Watt dan charge controller 1 unit sebesar 40 A. Sudut kemiringan sebesar 16 derajat. Estimasi biaya investasi yang dikeluarkans sebesar Rp.62.000.000,-
\end{abstract}

Kata Kunci: Roof Top, Solar Photovoltaic (SPV), off grid system

\begin{abstract}
At this time almost all residential houses use energy source from PLN network. Sources of electrical energy provided by PLN as much as possible savings in the use of electricity. One of the ways used is every home using Roof top panel solar photovoltaic, this aims to reduce the dependence of energy source from PLN. Based on the above, it is necessary to design the application of Roof top solar panel. In this research will be designed Roof top system off grid panel SPV as an alternative source of electrical energy. The design is for Solar Home System (SHS) system or residential house with solar radiation reference in Central Java region. Rooftop off grid solar photovoltaic system is designed using SPV panel components, batteries, inverters and charge controllers. Power capacity designed is 1,576.2 Watt and energy consumption per day of 4,260 Wh Number of batteries as many as 12 units with a capacity of each 310 Ah, SPV panel as much as 6 units capacity 225 Wp, 1 unit inverter of 1000 Watt and a charge controller 1 unit for $40 \mathrm{~A}$. Angle angle of 16 degrees. Estimated investment cost incurred at Rp.62.000.000, -
\end{abstract}

Keywords: Roof Top, Solar Photovoltaic (SPV), off grid system

\section{Pendahuluan}

Kebutuhan energi listrik setiap tahun mengalami peningkatan. Total kebutuhan listrik di Indonesia diperkirakan mencapai 172,34 TWh pada tahun 2020. Peningkatan kebutuhan listrik per tahun sekitar 6,5\% per tahun [1]. Ketersedian sumber energi dari fosil dan minyak bumi semakin lama akan semakin berkurang, sedangkan kebutuhan akan energi terus meningkat. Energi terbarukan merupakan salah satu sumber energi alternatif yang digunakan sebagai pengganti sumber energi fosil dan minyak bumi. Salah satu contoh sumber energi terbarukan adalah energi matahari. Indonesia merupakan Negara yang memiliki intensitas penyinaran matahari yang cukup tinggi yaitu mencapai $4500 \mathrm{Wh} / \mathrm{m} 2$ [2]. Roof top solar panel adalah panel SPV yang dipasang diatas rumah dengan tujuan untuk menghasilkan energi listrik, sehingga dapat mengurangi pemakaian daya listrik dari PLN bahkan tidak tergantung dari jaringan PLN. Roof top solar panel dapat dikoneksikan dengan jaringan PLN (on grid system) maupun berdiri sendiri (off grid system).
Pada saat ini hampir semua rumah tempat tinggal menggunakan sumber energi dari jaringan PLN. Sumber energi listrik yang disediakan oleh PLN sebisa mungkin dilakukan penghematan dalam pemakaian listrik. Salah satu cara yang digunakan adalah setiap rumah menggunakan Roof top solar panel, hal ini bertujuan untuk mengurangi ketergantungan sumber energi dari PLN. Berdasarkan hal tersebut maka perlu dilakukan perancangan dalam pengaplikasian Roof top solar panel.

Pada penelitian ini akan dirancang sistem Roof top off grid panel SPV sebagai sumber alternatif energi listrik. Perancangan diperuntukkan untuk sistem Solar Home System (SHS) atau rumah tempat tinggal dengan acuan radiasi matahari di wilayah Jawa Tengah.

\section{SISTEM ROOFTOP OFF GRID PANEL SOLAR PHOTOVOLTAIC}

A. Perancangan rooftop off grid Solar Photovoltaic

Komponen dalam perancangan rooftop offgrid solar photovoltaic antara lain panel SPV, baterai, Solar 
Charge Controller dan Inverter seperti ditunjukkan pada Gambar 1.

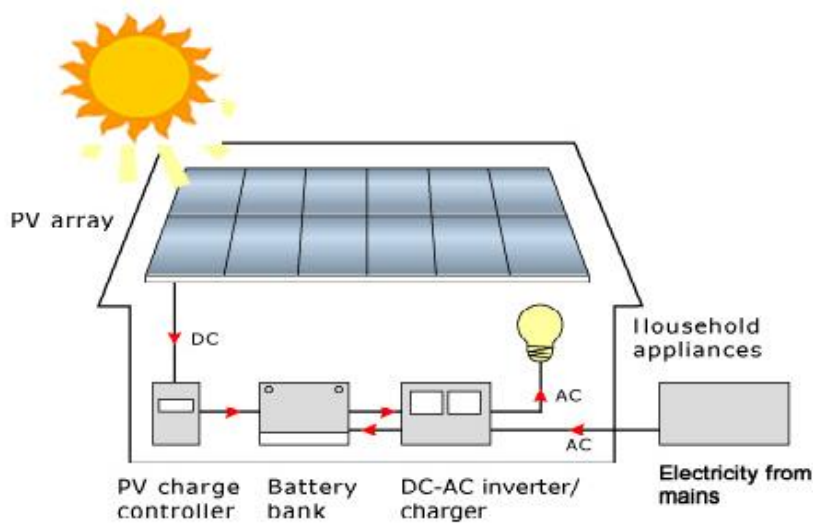

Typical Rooftop PV System

Gambar 1. Perancangan rooftop off grid solar photovoltaic

\section{B. Tahapan Perancangan}

Tahapan untuk merancang rooftop panel Solar Photovoltaic adalah:

1. Mengumpulkan data geografis kota

2. Menentukan total beban harian yang dipakai Evaluasi data beban harian ( Watt ) dan Energi (Wh) per har ini akan digunakan untuk menentukan kapasitas dan jumlah panel SPV. Total kebutuhan dikalikan dengan safety factor sistem PV sebesar 1.3.

3. Menentukan kapasitas baterai

4. Menentukan kapasitas panel SPV

5. Menentukan jarak antar panel SPV

6. Menentukan kapasitas Inverter dan Charge Controller

\section{METODE PENELITIAN}

Penelitian ini dilaksanakan dalam kurun waktu satu semester (6 bulan) dengan membagi dalam dua tahapan yaitu tahap persiapan, tahap kedua yaitu tahap perencanaan. Lokasi penelitian adalah di Laboratorium Konversi Energi Listrik, Teknik Elektro, Fakultas Teknik sebagai tempat perancangan dan rumah peneliti (Harmini) sebagai tempat pengambilan data beban. Variabel yang amati adalah kebutuhan beban, jumlah panel SPV, kapasitas panel SPV, kapasitas charge controller, kapasitas baterai, kapasitas baterai, penghantar dan pengaman, serta perhitungan biaya dengan acuan harga pada saat dilakukan penelitian

\section{A. Model dan Rancangan Penelitian}

Model dan rancangan yang digunakan dalam penelitian ini adalah perancangan sistem Roof top stand alone SPV system. Proses perencanaan berdasarkan pada skema yang ditunjukkan pada Gambar 2.

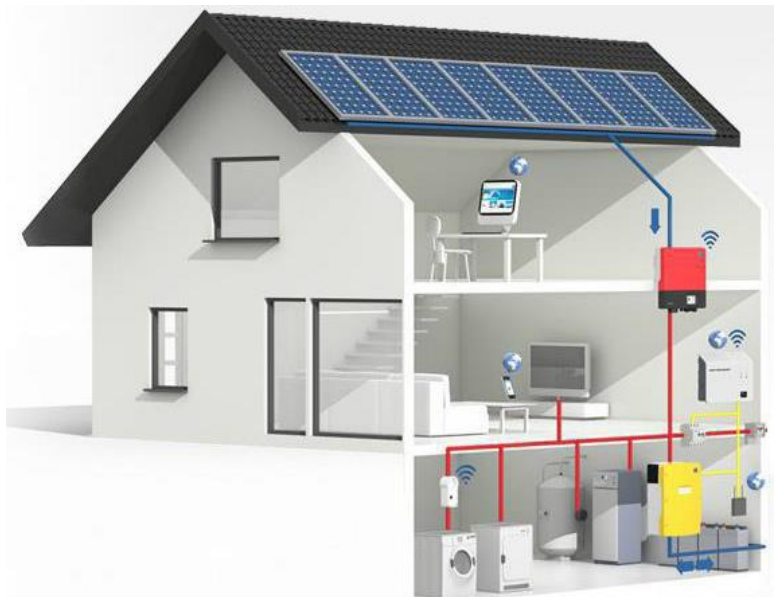

Gambar 2 Model sistem Roof top off grid SPV system[3]

\section{HASIL DAN PEMBAHASAN}

\section{A. Letak Geografis}

Letak dan kondisi geografis, kota semarang memiliki posisi astronomi diantara garis $6^{\circ} 50^{\prime}-7^{\circ} 10^{\prime}$ Lintang selatan dan garis $109^{\circ} 35^{\prime}-110^{\circ} 50^{\prime}$ Bujur Timur. Gambar 3 adalah peta kota Semarang

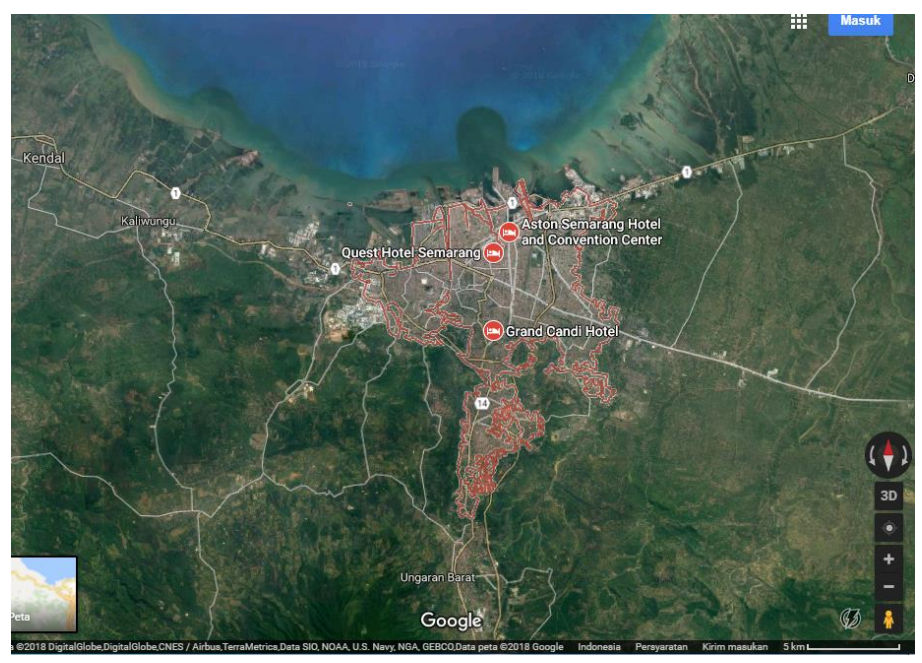

Gambar 3 Peta Kota Semarang

\section{B. Tahapan Perancangan}

1. Menghitung kebutuhan beban dalam waktu satu hari atau konsumsi daya

Kebutuhan beban atau konsumsi daya rumah tangga dalam satu hari ditunjukkan pada Tabel 1.

Tabel 1. Kebutuhan energi per hari

\begin{tabular}{cccccc}
\hline $\begin{array}{c}\text { N } \\
\text { o }\end{array}$ & Beban & $\begin{array}{c}\text { Daya } \\
\text { (Watt) }\end{array}$ & Jumlah Pemakaia & $\begin{array}{c}\text { Energi } \\
\text { n } \\
\text { (Jam) }\end{array}$ & (Watthour) \\
\hline 1 & Lampu pijar & 20 & 4 & 6 & 480 \\
2 & Lampu pijar & 40 & 2 & 6 & 480 \\
3 & Kipas Angin & 60 & 1 & 4 & 240 \\
4 & Kulkas & 75 & 1 & 24 & 900 \\
5 & Pompa & 125 & 1 & 3 & 375 \\
\hline
\end{tabular}




\begin{tabular}{lccccc}
\hline 6 & TV & 100 & 1 & 5 & 500 \\
7 & Radio & 25 & 1 & 5 & 125 \\
8 & Laptop & 90 & 1 & 5 & 450 \\
& Total & $\mathbf{5 3 5}$ & & & $\mathbf{3 . 5 5 0}$ \\
\hline
\end{tabular}

Jadi, Total konsumsi daya yang diperlukan adalah 535 Watt dan konsumsi energi sebesar 3.550 Wh per hari. Dengan mengasumsikan adanya kehilangan energi dalam sistem SPV maka total kebutuhan energi per hari tersebut dikalikan dengan safety faktor sebesar 1.2, sehingga

$$
\begin{aligned}
& \boldsymbol{E}_{T}=\boldsymbol{E}_{B} \boldsymbol{x} \text { Rugi dan safety factor } \\
& \boldsymbol{E}_{T}=\boldsymbol{E}_{B} \boldsymbol{x} \mathbf{1 . 2} \\
& \boldsymbol{E}_{T}=3.550 \boldsymbol{x} \mathbf{1 . 2} \\
& \boldsymbol{E}_{T}=4.260 \mathrm{Wh} / \mathrm{hari}
\end{aligned}
$$

Sedangkan total daya setelah dikalikan dengan safet factor adalah $535 \times 1.2=642$ Watt.

\section{Menghitung kapasitas baterai[8]}

Perhitungan kapasitas baterai mempertimbangkan faktor cuaca apabila terdapat konsidi tanpa ada matahari (No-sun or Black Day). Kondisi tersebut diasumsikan baterai dapat bertahan atau dapat digunakan dalam kurun waktu 3 hari dengan DOD (Depth of Discharge) sebesar $80 \%$. Rata-rata waktu beban adalah:

$$
\begin{aligned}
& \text { Weighted average load work time } \\
& \qquad=\frac{\sum \text { Energy }}{\sum \text { Power }} \\
& \text { Weighted average load work time }=\frac{4.260}{642}= \\
& 6.635 \mathrm{~h} \\
& \text { Average Discharge Rate }(h)=(\text { autonomy days } x \\
& \text { DOD } \\
& \text { Average Discharge Rate }(h)=(3 \times 6.635) / 0.8 \\
& \text { Average Discharge Rate }(h)=24.88 \mathrm{~h} \\
& C A P=(D X L) /(D O D \times \eta \text { out } x \mathrm{~V}) \\
& C A P=(3 X 4.260 \mathrm{Wh}) /(0.8 \times 0.9 \times 48) \\
& C A P=308.159 \mathrm{Ah}
\end{aligned}
$$$$
\text { Average Discharge Rate }(h)=(\text { autonomy days } x \text { weighted avgrageflaqdr work time } 15) /(0,9 \times 0,9 \times 0,9 \times 0,85)
$$

Effisiensi total (nout) adalah perkalian antara effisiensi inverter (0.92) dan effisiensi charge controller (0.98). Sesuai perhitungan maka kapasitas baterai yang digunakan adalah 308.159 Ah atau $310 \mathrm{Ah}$

Jika baterai yang digunakan adalah baterai dengan merk Trojan Baterai dengan tipe J150, 12 Volt, $5 \mathrm{Hr}$ rate capacity 120 Ah[Trojan, Data sheet], maka jumlah baterai yang digunaka adalah:

- $\quad$ Paralel : $308.159 \mathrm{Ah} / 120 \mathrm{Ah}=2.5$ atau 3 unit

- $\quad$ Seri $=48 \mathrm{~V} / 12 \mathrm{~V}=4$ unit

Jadi total baterai adalah $3 \times 4=12$ unit

3. Menghitung kapasitas panel SPV

Panel SPV SW 225 Mono SOLARWORLD Co dipilih dalam pada perancangan penelitian ini. Tabel 2menunjukkan spesifikasi panel SPV pada kondisi STC (Standart Temperature Condition) dan saat radiasi 800 W/m2 yang akan digunakan sebagai acuan perhitungan kapasitas panel SPV array. Lama penyinaran matahari dalam satu hari antara jam 09.00 sd 14.00 atau sekitar 5 jam per hari.

Tabel 2. Spesifikasi panel SPV

\begin{tabular}{llll}
\hline No & Keterangan & STC & $\mathbf{8 0 0 ~ W / m 2}$ \\
\hline 1 & Pmax & $225 \mathrm{Wp}$ & $163 \mathrm{Wp}$ \\
2 & Voc & $37,3 \mathrm{~V}$ & $33,7 \mathrm{~V}$ \\
3 & Vmpp & $29,7 \mathrm{~V}$ & $26,8 \mathrm{~V}$ \\
4 & Isc & $8,13 \mathrm{~A}$ & $6,65 \mathrm{~A}$ \\
5 & Impp & $7,59 \mathrm{~A}$ & $6,07 \mathrm{~A}$ \\
\hline
\end{tabular}

Panel SPV output current $=L /(V x \eta 1 \times \eta 2 \times h)$ Panel SPV output current $=4.260 \mathrm{Wh} /(48 \mathrm{Vx} 0,9$ $x 0,7 \times 5 \mathrm{~h}$ )

Panel SPV output current $=28,17 \mathrm{~A}$

Dimana $\eta 1$ adalah rugi-rugi kabel dan $\eta^{2}$ adalah effisiensi baterai

Jumlah panel SPV yang dirangkai paralel adalah = $28,17 \mathrm{~A} / 8,13 \mathrm{~A}=3.46=3$ unit

Jumlah panel SPV yang dirangkai seri adalah $=48 \mathrm{~V} /$ $29,7 \mathrm{~V}=1,6=2$ unit

Total panel yang digunakan adalah 3 × $2=6$ unit

$P V$ array power output $=$ Daily electricity consumption / Minimum sunshine time

$P V$ array power output $=4.260 \mathrm{Wh} / 5 \mathrm{~h}=852$ Watt

Safe factor $=(1+$ Surplus capacity $) /($ Battery efficiency $x$ Temperature loss factor $x$ dust loss factor $x$ controller efficiency)

Nilai Surplus capacity berkisar antara $10 \%-15 \%$, perancangan ini diambil $15 \%=0.15$

Output x safe factor $=852 \mathrm{~W}$ x $1.85=1.576,2 \mathrm{Watt}$

Total numbers $=1.576,2 \mathrm{~W} / 225 \mathrm{~W}=5,7=6$ unit panel SPV

\section{Menghitung jarak panel}

Jarak panel SPV ditentuka berdasarkan tinggi panel SPV, sudut deklinasi matahari dan lintang selatan daerah. Sudut deklinasi matahari pada bulan agustus adalah +10 derajat, linteng selatan kota semarang adalah 6 derajat, sesuai dengan ilustrasi pada Gambar 4 maka dapat dicari jarak antar panel SPV. Berdasarkan data sheet, panel SPV memiliki L (panjang ) $=1675 \mathrm{~mm}$, Lebar $(\mathrm{w})$ $=1001 \mathrm{~mm}$ dan Tebal $(\mathrm{H})=34 \mathrm{~mm}, \mathrm{X}=1675 \mathrm{~mm}, \beta=6^{\circ}$

$$
\begin{aligned}
& D 1=X \cos \beta \\
& D 1=1675 \cos 6^{\circ} \\
& D 1=1665 \mathrm{~mm} \\
& H=X \sin \beta \\
& H=1675 \sin 6^{\circ} \\
& H=175,08 \mathrm{~mm} \\
& D 2=H \tan (\delta+L) \\
& D 2=175,08 \tan \left(10^{\circ}+6^{\circ}\right) \\
& D 2=50,18 \mathrm{~mm} \\
& D_{T}=D 1+D 2
\end{aligned}
$$

Safe factor $=1,85$ 


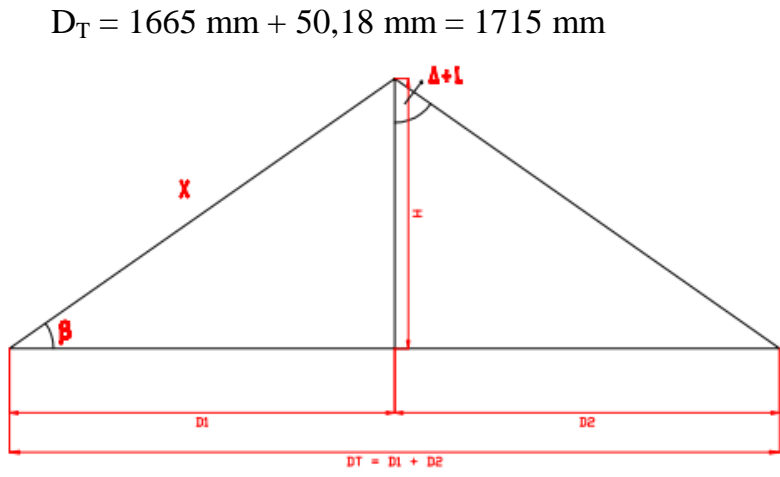

Gambar 4. Ilustrasi penempatan panel SPV

Gambar 4 dan 5 menunjukkan penempatan panel SPV dengan sudut kemiringan $16^{\circ}$ dan gambar penempatan panel SPV array dengan jumlah 6 yaitu 3 paralel dan 2 seri.

\section{Menghitung kapasitas inverter[4]}

Kapasitas inverter adalah perbandingan antara daya beban dengan effisiensi inverter yaitu 0,8 , sedangkan controller current adalah perbandingan kapasitas sistem dengan tegangan dikalikan loss factor.

Inverter Capacity = Load Power $/ 0.8$

Inverter Capacity $=642 \mathrm{~W} / 0.8=802.5 \mathrm{Watt}=$ 1000 Watt

Inverter yang digunakan adalah SMARTFORMER FOR SUNNY ISLAND [5]

Controller current $=$ System Capacity $/($ Voltage $x$ Loss Factor)

Controller current $=1576.2 \mathrm{~W} /(48 \times 0.85)=38.63$ $A=40 \mathrm{~A}$

Charge controller yang digunakan adalah Steca Tarom[6]

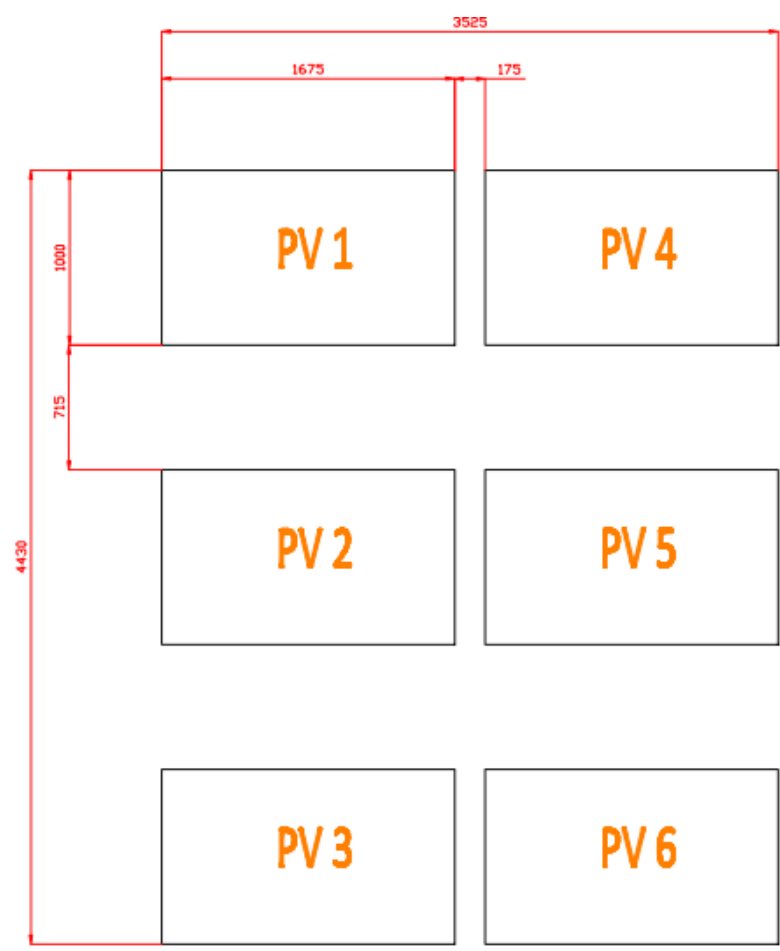

Gambar 5.5. Layout panel SPV

\section{Estimasi Biaya}

Sistem SPV memiliki kapasitas 1.576,2 Watt atau 1.6 KW, dengan estimasi biaya untuk pengadaaan komponen panel SPV, off grid inverter, batteray, charge controller, AC Circuit Bracket, kabel and PV panel Mounting rack. Tabel 3 menunjukkan jenis-jenis komponen dan harga masing-masing komponen.

Tabel 3. Estimasi Biaya

\begin{tabular}{lllccc}
\hline $\begin{array}{c}\text { Nama } \\
\text { Komponen }\end{array}$ & \multicolumn{1}{c}{ Merk } & \multicolumn{1}{c}{ Tipe } & Jml & $\begin{array}{c}\text { Harga } \\
\text { /unit } \\
\text { (Juta) }\end{array}$ & $\begin{array}{c}\text { Total } \\
\text { (Juta) }\end{array}$ \\
\hline SPV Panel & Solarworld & SW 225 & 6 & 1.1 & 6.6 \\
Inverter & SMA & Smartformer & 1 & 12 & 12 \\
Controller & Steca & $\begin{array}{l}\text { Power } \\
\text { tarom 4140 }\end{array}$ & 1 & 10 & 10 \\
Baterai & Trojan & j150 & 12 & 2.8 & 33.6 \\
Mounting & & & & & \\
Breaker & & & & & \\
Kabel & & & & & $\mathbf{6 2 . 2}$ \\
Total & & & & &
\end{tabular}

Estimasi biaya total yang dikeluarkan adalah sebesar Rp 62.200.000,- dengan kapasitas daya yang dibangkitkan 
sebesar 1576 watt, sehingga per watt memerlukan biaya Rp 39.467,-

\section{KESIMPULAN}

Dari penelitian yang telah dilakukan dapat diambil kesimpulan sebagai berikut:

1. Sistem rooftop off grid solar photovoltaic dirancang dengan menggunakan komponen panel SPV, baterai, inverter dan charge controller

2. Kapasitas daya yang dirancang adalah $1.576,2$ Watt dan konsumsi energi per hari sebesar 4.260 Wh

3. Jumlah baterai sebanyak 12 unit dengan kapasitas masing-masing $310 \mathrm{Ah}$, panel SPV sebanyak 6 Unit kapasitas $225 \mathrm{Wp}$, inverter 1 unit sebesar 1000 Watt dan charge controller 1 unit sebesar $40 \mathrm{~A}$

4. Sudut kemiringan sebesar 16 derajat

\section{Daftar Pustaka}

Muchlis \& Permana. 2006. Proyeksi Kebutuhan Listrik PLN TAHUN 2003 S.D 2020. Jurnal Pengembangan Sistem Kelistrikan Dalam Pembangunan Nasional Jangka Panjang: $19-29$.

Yuliarto, B. 2011. Solar Sel Sumber Energi Terbarukan Masa Depan, www.esdm.go.id/berita/artikel/, diakses pada 18 Agustus 2017

Albadi,M,dkk, 2014,'Design of a 50 kW Solar PV Roof top system", International Journal of Smart Grid and Clean Energy, College of Engineering Sultan Qaboos University

Sungrow,Co "Off grid photovoltaic power generation system”, November 2011

SMA Sunny Island "Smart Battery Inverter Data Sheet" http://www.sma.de/en/product/off-gridinverter/smartformer-for-sunny-island.html

Steca Power Tarom,"Charge Controller 4140 Data Sheet", http://www.steca.com/stec-apower-tarom

Datasheet Smart Solar Charge Controller with screw or MC4 PV connection MPPT 150/85 \& MPPT 150/100, http://www.victronenergy.com diakses pada 16 Januari 2017

Dunlop, J., 1997, "Batteries and Charge Control in Stand-Alone Photovoltaic Systems: Fundamentals and Application," Contract Report, Florida Solar Energy Center,Cocoa, FL

E. Lorenzo,"Solar Electricity", http://books.google.co.id/books/Solar diakses pada 16 Januari 2017

Jatmiko; Asy'ari, H; Purnama, M. 2011. Pemanfaatan Sel Surya dan Lampu LEDUntuk Perumahan. Seminar Nasional Teknologi Informasi \& Komunikasi Terapan. ISBN 979-26-0255-0.

Joachim Seel G.B., R. Wiser, Why Are Residential PV Prices in Germany So Much Lower Than in the United States? Environmental Energy, 2010. 